\title{
First trimester uterine artery Doppler screening in the prediction of adverse pregnancy outcomes
}

\author{
Jacqueline A. Jayson'1, Kavita Mandrelle ${ }^{1 *}$, Tapasya Dhar ${ }^{1}$, Subhash Singla ${ }^{2}$
}

\begin{abstract}
${ }^{1}$ Department of Obstetrics and Gynecology, ${ }^{2}$ Department of Radiodiagnosis, Christian Medical College and Hospital, Ludhiana, Punjab, India
\end{abstract}

Received: 04 August 2021

Accepted: 02 September 2021

\author{
*Correspondence: \\ Dr. Kavita Mandrelle, \\ E-mail: kavitamandrelle@gmail.com
}

Copyright: ( $)$ the author(s), publisher and licensee Medip Academy. This is an open-access article distributed under the terms of the Creative Commons Attribution Non-Commercial License, which permits unrestricted non-commercial use, distribution, and reproduction in any medium, provided the original work is properly cited.

\begin{abstract}
Background: Uterine artery Doppler waveform has been extensively studied as a predictive marker for the later development of preeclampsia and fetal growth restriction. Therefore, uterine artery doppler has emerged as a good test for the prediction of preeclampsia, being simple to perform, reproducible and non-invasive. The present study was done to evaluate the first trimester uterine artery Doppler in the prediction of adverse pregnancy outcome.

Methods: This was a prospective cohort study for all pregnant women attending antenatal clinic during 11-14 weeks of gestation at Christian medical college and hospital, Ludhiana, during a period of 18 months. Study population of (n 270) was taken. A pre-designed case record was filled at the time of registration. After taking informed consent, these women underwent ultrasound for uterine artery Doppler pulsatility index along with nuchal translucency \& nasal bone scan by transabdominal ultrasound. Patients were followed up throughout the gestation to find out the development of any adverse pregnancy outcomes (early onset preeclampsia, early onset fetal growth restriction, late onset preeclampsia, late onset fetal growth restriction, oligohydramnios, placental abruption and stillbirth).

Results: In our study, about $75 \%$ of antenatal women were found to have normal first trimester uterine artery pulsatility index and the rest $25 \%$ had abnormal pulsatility index. About $40 \%$ of women with abnormal dopplers developed complications associated to hypertensive disorders and adverse pregnancy outcomes, while $60 \%$ went on to have a normal pregnancy. It was observed that $13.2 \%$ developed gestational hypertension, $10.29 \%$ developed pulmonary embolism, $1.47 \%$ developed eclampsia, $22.05 \%$ developed oligohydramnios, $42.64 \%$ developed fetal growth restriction, $4.41 \%$ developed placental abruption and $5.88 \%$ delivered stillbirth neonates.

Conclusions: As hypertensive disorders of pregnancy pose a great risk of maternal and fetal morbidity and mortality, an evolution of Doppler studies have proven to be beneficial. Doppler ultrasound was found to be a valuable modality in the evaluation of fetal and placental circulation as well as in the prediction of pregnancy outcomes. According to the receiver operating characteristic curve obtained in our study, sensitivity and specificity of first trimester uterine artery pulsatility index was predictive for pregnancy complications and adverse outcomes.
\end{abstract}

Keywords: Uterine artery doppler, Pulsatility index, Preeclampsia, First trimester

\section{INTRODUCTION}

Uterine artery Doppler waveform has been extensively studied in the second trimester of pregnancy as a predictive marker for the later development of preeclampsia and fetal growth restriction. The use of
Doppler interrogation of this vessel in the first trimester has gained momentum in the recent years. ${ }^{1}$ As hypertensive disorders of pregnancy form a major bulk of adverse outcomes during pregnancy and delivery, many studies have been done on the various methods to predict adverse outcomes. Some of these studies have shown the 
utility of Doppler velocimetry of uterine arteries for the anticipation of hypertensive disorders in pregnancy and fetal growth restriction. ${ }^{2}$ Therefore, uterine artery Doppler emerged as a good test for the prediction of preeclampsia, being simple to perform, reproducible and non-invasive. ${ }^{3}$ It is recommended that during the first prenatal visit, a woman's level of risk for adverse pregnancy outcome should be evaluated, so that a schedule for her prenatal visits can be formulated. Increasingly research is geared towards early identification of risks, thereby allowing early commencement of management strategies, through pharmacological intervention in those at high risk and to minimize the risk of adverse outcome for those who develop pre-eclampsia, including facilitation of an appropriate level of pregnancy monitoring, determining the appropriate time and place of delivery. ${ }^{4-6}$

Hypertensive disorders represent the most common medical complication of pregnancy affecting $7-15 \%$ of all gestations and account for approximately a quarter of all antenatal admissions. ${ }^{7}$ About $2-8 \%$ of pregnancies are complicated with preeclampsia, which is associated with significant morbidity and mortality. Hypertensive disorders are the second most common cause of maternal death worldwide, affecting 5-10 \% of pregnancies. ${ }^{8}$ Hypertension along with haemorrhage and infection, forms the deadly triad that contributes to morbidity and mortality during pregnancy and childbirth. ${ }^{9}$

Preeclampsia is strongly associated with fetal growth restriction, low birth weight, spontaneous or iatrogenic preterm delivery, respiratory distress syndrome and admission to neonatal intensive care unit. ${ }^{10}$ Preeclampsia contributes to $15 \%$ of preterm deliveries and between $9 \%$ to $26 \%$ maternal deaths worldwide. ${ }^{11}$ Preeclampsia and fetal growth restriction cause $6 \%$ and $10 \%$ of perinatal deaths respectively. ${ }^{12}$

In normal pregnancy, the feto-placental circulation acts as a low resistance system unit. Thus, blood velocity waveforms in umbilical artery shows continuous forward flow throughout the cardiac cycle. But impaired placental perfusion, which is one of the hallmarks of preeclampsia, can be assessed by measuring flow waveform ratios or by detecting diastolic notching of uterine and umbilical vessels. Overall, first trimester doppler interrogation of the uterine artery performs better in the prediction of early onset than late onset preeclampsia.

Clinical risk assessment for preeclampsia is carried out in the first trimester for early identification of women who may benefit from preventive treatment, such as Aspirin. ${ }^{13}$ Currently there is no treatment which can prevent all cases of preeclampsia. There is evidence that low dose aspirin started early in pregnancy has some role in reducing the incidence of adverse pregnancy outcome in significant number of cases. Prophylactic aspirin reduces early onset preeclampsia and preterm delivery by $10 \% .^{14}$ 21

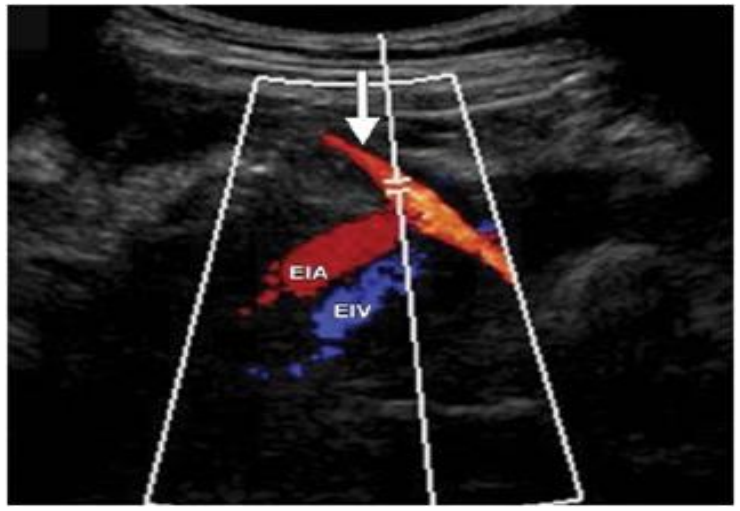

Figure 1: Color Doppler flow ultrasound (US) of the sample volume placed in the uterine artery (arrow) with an angle of insonation of about $30^{\circ}$. The uterine artery perfuses the myometrium, so flow is toward the transducer, because the uterine artery is a branch of the internal iliac artery deep in the maternal pelvis. ${ }^{22}$

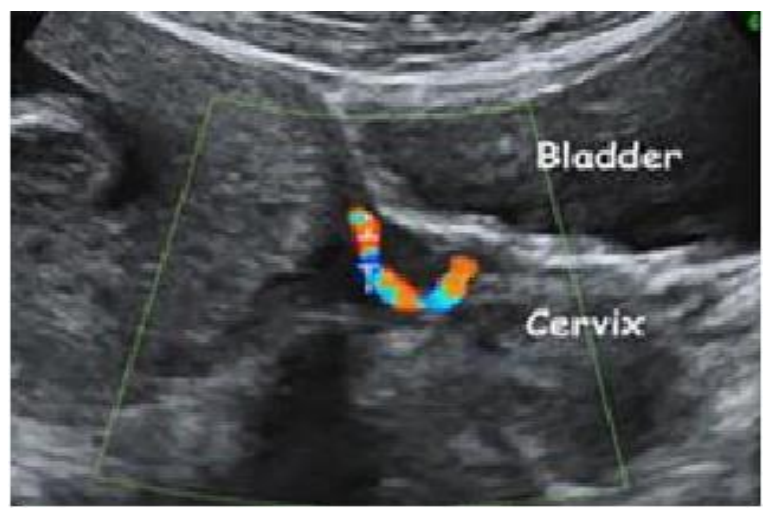

Figure 2: Identification of the uterine artery at the level of internal OS. ${ }^{23}$

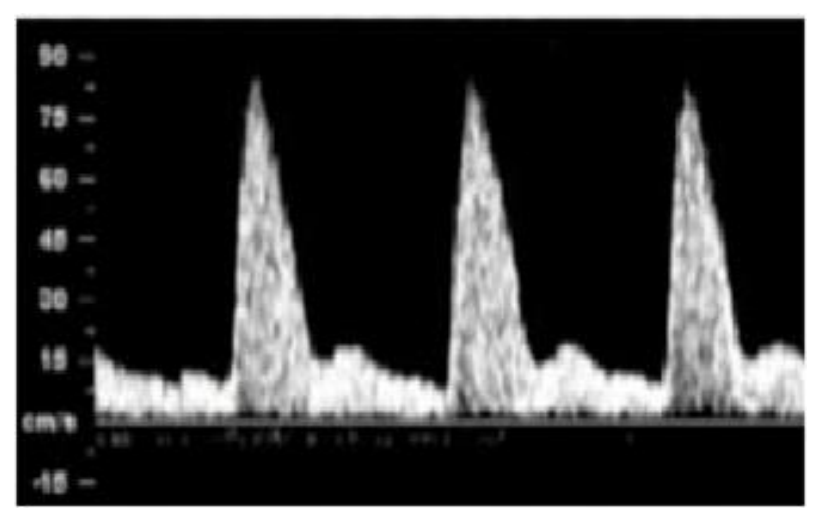

Figure 3: Typical waveforms of the uterine artery Doppler in the first trimester of pregnancy. ${ }^{23}$

\section{Objectives}

The present study aims to evaluate the first trimester uterine artery Doppler in the prediction of adverse pregnancy outcome. 


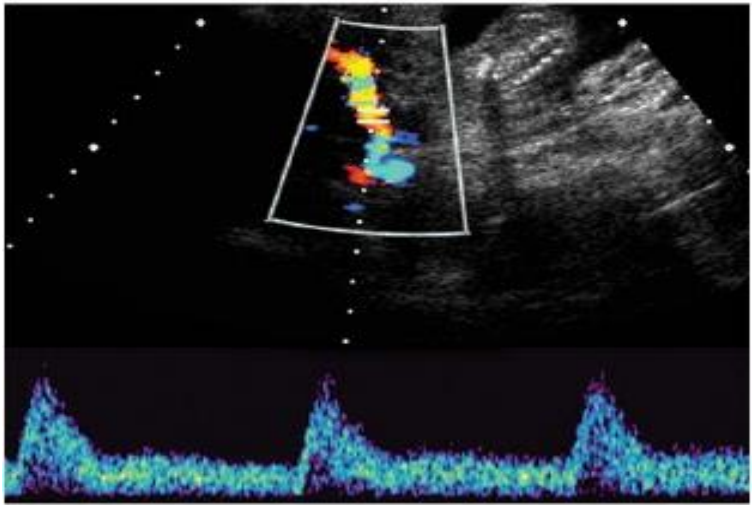

Figure 4: Color Doppler duplex US of a normal waveform with no notch and continuous diastolic flow. ${ }^{22}$

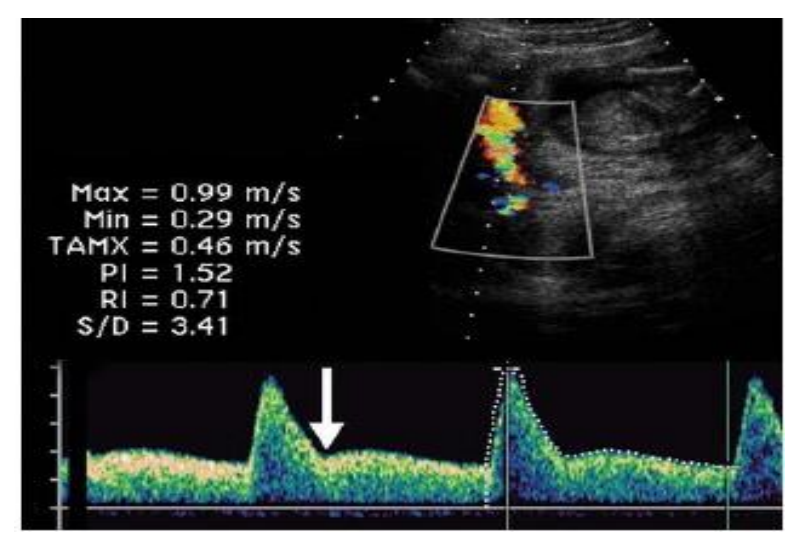

Figure 5: Color Doppler duplex US of an abnormal waveform with a mild notch (arrow) in diastole but preserved end diastolic flow. Max=maximum (same as peak systolic velocity), Min=minimum (same as end diastolic velocity), $\mathrm{PI}=$ pulsatility index, $\mathrm{RI}=$ resistance index, TAMX=time averaged maximum velocity. ${ }^{22}$

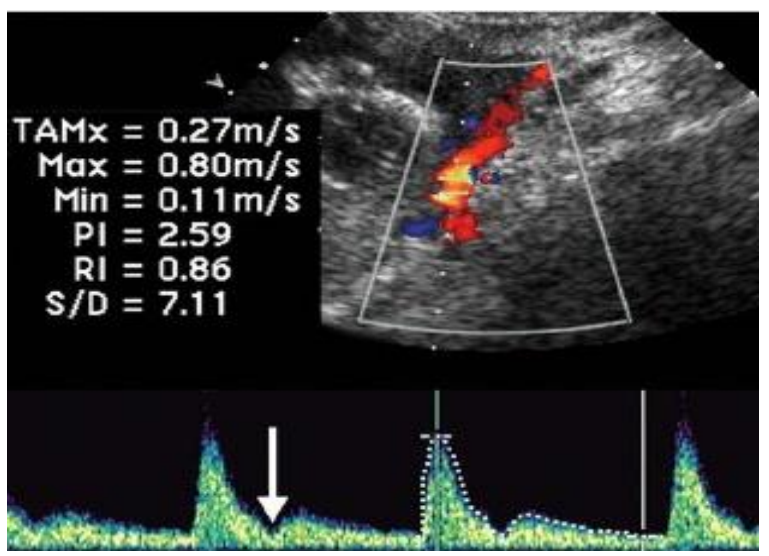

Figure 6: Color Doppler duplex US of an abnormal waveform with marked notching (arrow) and decreased end diastolic flow. Max=maximum (same as peak systolic velocity), Min=minimum (same as enddiastolic velocity), $\mathrm{PI}=$ pulsatility index, $\mathrm{RI}=$ resistance index, TAMx=time averaged maximum velocity ${ }^{22}$

\section{METHODS}

This is a prospective cohort study conducted in the outpatient department (OPD) of department of obstetrics and gynaecology over a period of 18 months from 01 November 2018 to 30 April 2020 among pregnant women screened between 11-14 weeks of gestation, who met the inclusion and exclusion criteria.

\section{Inclusion criteria}

Inclusion criteria for current study were; all singleton pregnancies and patients willing to follow up in antenatal clinic.

\section{Exclusion criteria}

Exclusion criteria for current study were; multiple gestation detected <14 weeks, fetal abnormalities detected $<14$ weeks and patients on treatment for hypertensive disorders.

\section{Study procedure}

A written informed consent, after explaining the objectives of the study was taken. Case report form was obtained which will ascertain the age, parity, last menstrual period, gestational age, expected date of delivery, obstetric history (gestational hypertension, preeclampsia, eclampsia, gestational diabetes mellitus, fetal growth restriction, antepartum haemorrhage, stillbirth), medical history (hypertension, diabetes mellitus, hypothyroidism, antiphospholipid antibody syndrome) and family history (hypertension and diabetes mellitus). This was followed by uterine artery Doppler ultrasound between 11-14 weeks of gestation, along with scan for nuchal translucency and nasal bone.

Ultrasound was performed by a radiologist. Siemen's or Phillips ultrasound machine was used. A 5 or $3.5 \mathrm{MHz}$ curvilinear transabdominal transducer was used. Using pulsed wave Doppler, flow velocity waveforms from the ascending branch of the uterine artery at the point closest to the internal os are obtained bilaterally. The angle of insonation should be less than 30 degree, in order to achieve the highest systolic diastolic velocities. When three similar consecutive waveforms are obtained, the pulsatility index (PI) was measured. The mean PI is calculated as the average reading from each side combined. Patients were managed accordingly depending on the standard of care. Follow up of patients was done by repeating ultrasound in the second trimester between 18-20 weeks along with level II scan and later in the third trimester between 32-36 weeks along with scan for fetal well-being. Patients were followed up until delivery. Mode of delivery, period of gestation at delivery and birth weight were also noted. 


\section{Outcome measures}

Outcome of the study was a composite dichotomous variable. It includes early onset preeclampsia, late onset preeclampsia, early onset fetal growth restriction, late onset fetal growth restriction, placental abruption, oligohydramnios, and stillbirth.

\section{Sample size}

Total number of singleton pregnant women attending the antenatal outpatient department, between 11 - 14 weeks of gestation in a year was 270 . We tried to take all consecutive pregnant woman in the study.

\section{Statistical analysis}

The study was carried out on 280 patients. Data was classified into abnormal normal uterine artery pulsatility index $(\mathrm{PI} \geq 1.5)$ and normal uterine artery pulsatility index $(\mathrm{PI}<1.5)$. The presence or absence of pregnancy complications and adverse outcomes were noted. Along with that sensitivity, specificity, positive and negative predictive values were calculated, and occurrence was reported as contingency table. A $\mathrm{P}$ value of less than 0.05 was considered as significant. Exact Clopper-Pearson confidence intervals for confidence interval were calculated. PI was reported as mean \pm SD and median (interquartile range). ROC curve was made to establish the efficiency of Doppler test. Data was entered using Microsoft Office Excel and was analysed by appropriate statistical methods including tests of significance using SPSS (statistical packages for social sciences, version 21.0).

\section{RESULTS}

The mean age of antenatal women was $28.5 \pm 4.1$ years. The number of antenatal women who developed abnormal (PI $\geq 1.5$ ) Doppler's was $25 \%$. The maximum numbers $(47.8 \%)$ of antenatal women were between 26 30 years of age and $57.1 \%$ of them had abnormal first trimester uterine artery pulsatility index. The number of antenatal women who were primigravida was $45 \%$ and $26.2 \%$ of them developed abnormal Doppler's in the first trimester of pregnancy. The number of antenatal women with abnormal first trimester Doppler who developed at least one of the pregnancy complications and adverse outcomes was $40 \%$. It was also observed that $19 \%$ of women with normal uterine artery Doppler findings of first trimester developed pregnancy complications and adverse outcomes. It has been observed that among all the women studied, $13.2 \%$ developed gestational hypertension, $10.29 \%$ developed PE, $1.47 \%$ developed eclampsia, and $22.05 \%$ developed oligohydramnios. FGR was seen in $42.64 \%$, placental abruption in $4.41 \%$ and stillbirth in $5.88 \%$. The number of antenatal women who developed pregnancy complications and adverse outcomes in the second trimester of pregnancy was $33.8 \%$.
It was observed in our study that antenatal women with abnormal Doppler's (PI $\geq 1.5$ ), had significant $\mathrm{P}$ value for gestational hypertension (0.0314), oligohydramnios (0.0004) and FGR (0.0022) as abnormal Doppler's in the first trimester predict pregnancy complications. The number of antenatal women who delivered during early term ( 37 to $38+6$ weeks) was $50.3 \%$. In the group of antenatal women who had delivered during early term period, $57.1 \%$ had abnormal uterine artery pulsatility index in the first trimester of pregnancy. Women who delivered between 32 to $36+6$ weeks constituted $14.64 \%$ of all antenatal women in the study. Abnormal uterine artery pulsatility index was found in $7.14 \%$ of these women. There was only one antenatal woman in the group who had abnormal Doppler's detected in the first trimester of pregnancy, who delivered between 28 to $31+6$ weeks of gestation (very preterm period). There was no statistical significance in the mode of delivery; $47.1 \%$ vaginal delivery, $2.9 \%$ instrumental delivery and $50 \%$ lower segment caesarean section (LSCS). The number of neonates whose birth weight was between 2000-2499 gms constituted 15.4\%. Abnormal Doppler finding among mothers of these neonates was seen in $24.28 \%$. Thus, the $\mathrm{p}$ value was significant $(0.023)$. ROC curve of first trimester uterine artery PI had an area under the curve (AUC) of 0.659 ( $\mathrm{p}$ value=0.000) which represents fair accuracy. A ROC curve was generated to determine the sensitivity and specificity of first trimester uterine artery PI for the prediction of pregnancy complications and adverse outcomes. It was found that sensitivity of first trimester uterine artery pulsatility index for the prediction of pregnancy complications and adverse outcomes was $42.03 \%$ and specificity was $80.57 \%$. The positive predictive value was $41.43 \%$ and negative predictive value was $80.95 \%$. ROC curve of first trimester uterine artery PI had an AUC of 0.659 (p value $=0.000$ ) which represents fair accuracy.

\section{DISCUSSION}

\section{Fetal growth restriction}

FGR developed in $42.64 \%$ of the total study population. It developed in $11.76 \%$ of the antenatal women during the second trimester, and $30.88 \%$ of women in third trimester. It was also seen that the rate of FGR was high $(20 \%)$ in the women who had abnormal first trimester uterine artery pulsatility index, when compared to $7 \%$ of women who had normal uterine artery Doppler. Therefore, $\mathrm{p}$ value was significant, which was 0.0022 . A meta-analysis done by Velathur et al predicted $15.4 \%$ of FGR and higher sensitivity of $39.2 \%$ for early onset FGR. ${ }^{15}$ Study by Plasencia et al reported high detection rate of FGR (12.6\%) when compared to hypertensive disorders. ${ }^{16}$ A study done by Ratiu et al which analysed uterine artery Doppler between 19 to 22 weeks of gestation reported 80 cases with FGR among 1472 women studied. The prevalence of FGR in their study was $5.4 \% .^{17}$ 
Table 1: Distribution of study participants according to various parameters $(n=280)$.

\begin{tabular}{|c|c|c|}
\hline Parameters & Frequency & $\%$ \\
\hline \multicolumn{3}{|l|}{ Age (years) } \\
\hline$\leq 20$ & 3 & 1.07 \\
\hline $21-25$ & 66 & 23.57 \\
\hline $26-30$ & 134 & 47.8 \\
\hline $31-35$ & 58 & 20.7 \\
\hline $36-40$ & 19 & 6.7 \\
\hline \multicolumn{3}{|c|}{ Distribution of antenatal women according to age } \\
\hline Parity & Frequency & $\%$ \\
\hline Primigravida & 126 & 45 \\
\hline Multigravida & 154 & 55 \\
\hline \multicolumn{3}{|c|}{ Distribution of antenatal women according to parity } \\
\hline Age (years) & $\mathrm{PI} \geq 1.5(\mathrm{~N}=70)$ Frequency $(\%)$ & PI <1.5 (N=210) Frequency (\%) \\
\hline$\leq 20$ & 0 & $3(1.4)$ \\
\hline $21-25$ & $9(12.8)$ & $57(27.1)$ \\
\hline $26-30$ & $40(57.1)$ & $94(44.76)$ \\
\hline $31-35$ & $15(21.4)$ & $43(20.4)$ \\
\hline $36-40$ & $6(8.5)$ & $13(6.1)$ \\
\hline \multicolumn{3}{|c|}{ Association of first trimester uterine artery pulsatility index with age of antenatal women } \\
\hline Parity & $\mathrm{PI} \geq 1.5(\mathrm{~N}=70)$ Frequency $(\%)$ & PI <1.5 (N=210) Frequency $(\%)$ \\
\hline Primigravida & $33(26.2)$ & $93(73.8)$ \\
\hline Multigravida & $38(24)$ & $117(76)$ \\
\hline \multicolumn{3}{|c|}{ Association of first trimester uterine artery pulsatility index with parity of antenatal women } \\
\hline \multicolumn{3}{|c|}{$P$ value $=0.677$} \\
\hline Adverse pregnancy outcomes & Frequency $(\mathrm{N}=68)$ & $\%$ \\
\hline Gestational hypertension & 9 & 13.2 \\
\hline Preeclampsia & 7 & 10.29 \\
\hline Eclampsia & 1 & 1.47 \\
\hline Oligohydramnios & 15 & 22.05 \\
\hline Fetal growth restriction & 29 & 42.64 \\
\hline Placental abruption & 3 & 4.41 \\
\hline Stillbirth & 4 & 5.88 \\
\hline \multicolumn{3}{|c|}{ Distribution of antenatal women according to pregnancy complications /adverse pregnancy outcomes } \\
\hline Period of gestation at delivery (weeks) & Normal PI (N=210) Frequency $(\%)$ & Abnormal PI (N=70) Frequency $(\%)$ \\
\hline 28 to $31+6$ & 0 & $1(1.42)$ \\
\hline 32 to $33+6$ & $2(0.9)$ & 0 \\
\hline 34 to $36+6$ & $34(16.19)$ & $5(7.14)$ \\
\hline 37 to $38+6$ & $101(48)$ & $40(57.1)$ \\
\hline 39 to $40+6$ & $72(34.28)$ & $24 \quad 34.28)$ \\
\hline$>41$ & $1(0.47)$ & 0 \\
\hline \multicolumn{3}{|c|}{ Association of first trimester uterine artery pulsatility index with gestational age at delivery } \\
\hline Mode of delivery & Frequency & $\%$ \\
\hline Vaginal delivery & 132 & 47.1 \\
\hline Instrumental delivery & 8 & 2.9 \\
\hline LSCS & 140 & 50 \\
\hline \multicolumn{3}{|c|}{ Distribution of antenatal women according to mode of delivery } \\
\hline$P$ value $=\mathbf{0 . 7 3 3 0}$ & & \\
\hline
\end{tabular}

\section{Oligohydramnios}

The second most common adverse effect in the present study was oligohydramnios, developing in $22.05 \%$ women. About $13.2 \%$ of the antenatal women developed oligohydramnios in the third trimester of pregnancy when compared to $10.29 \%$ who developed it in the second trimester. It has been observed that $14.28 \%$ of antenatal women with abnormal uterine artery pulsatility index developed oligohydramnios when compared to only 2.85 $\%$ of women with normal Doppler findings. Therefore, $\mathrm{p}$ value was significant, which was 0.0004 . 
Table 2: Uterine pulsatility index and complications $(\mathrm{n}=\mathbf{2 8 0})$.

\begin{tabular}{|c|c|c|c|}
\hline Category & Criteria & $\mathbf{N}$ & $\%$ \\
\hline Abnormaluterine arterydopplerin firsttrimester & $\mathrm{PI} \geq 1.5$ & 70 & 25 \\
\hline Normaluterine arterydopplerin firsttrimester & PI $<1.5$ & 210 & 75 \\
\hline \multicolumn{4}{|c|}{ Distribution of antenatal women according to first trimester uterine artery pulsatility index } \\
\hline Outcome of pregnancy & $\begin{array}{l}\mathrm{PI} \geq 1.5(\mathrm{~N}=70) \\
\text { Frequency }(\%)\end{array}$ & $\begin{array}{l}\text { PI<1.5 }(\mathrm{N}=210) \\
\text { Frequency }(\%)\end{array}$ & $\begin{array}{l}\text { Total } \\
\text { Frequency }(\%)\end{array}$ \\
\hline Adverse outcomesin pregnancy & $28(40)$ & $40(19)$ & $68(24.2)$ \\
\hline Normal pregnancy & $42(60)$ & $170(81)$ & $212(75.71)$ \\
\hline \multicolumn{4}{|c|}{$\begin{array}{l}\text { Distribution of antenatal women according to first trimester uterine artery pulsatility index and adverse pregnancy } \\
\text { outcomes }\end{array}$} \\
\hline Adverse pregnancy outcomes & $\begin{array}{l}\text { Second trimester } \\
\text { (14 to } 27+6 \text { weeks) } \\
\text { Frequency (\%) }\end{array}$ & $\begin{array}{l}\text { Third trimester } \\
\text { (28 to } 40 \text { weeks) } \\
\text { Frequency }(\%)\end{array}$ & $\begin{array}{l}\text { Total } \\
(\mathbf{N}=68)\end{array}$ \\
\hline Gestational hypertension & $4(5.88)$ & $5(7.3)$ & 9 \\
\hline Preeclampsia & $2(2.94)$ & $5(7.3)$ & 7 \\
\hline Eclampsia & $1(1.47)$ & $0(0)$ & 1 \\
\hline Oligohydramnios & $7(10.29)$ & $9(13.2)$ & 15 \\
\hline FGR & $8(11.76)$ & $21(30.88)$ & 29 \\
\hline Placental abruption & $1(1.47)$ & $2(2.94)$ & 3 \\
\hline Stillbirth & 0 & $4(5.88)$ & 4 \\
\hline \multicolumn{4}{|c|}{ Trimester wise distribution of antenatal women according to pregnancy complications/adverse pregnancy outcome } \\
\hline Adverse pregnancy outcomes & $\begin{array}{l}\mathrm{PI} \geq 1.5(\mathrm{~N}=70) \\
\text { Frequency }(\%)\end{array}$ & $\begin{array}{l}\text { PI }<1.5(\mathrm{~N}=210) \\
\text { Frequency }(\%)\end{array}$ & P value \\
\hline Gestational hypertension & $5(7.14)$ & $4(1.9)$ & 0.0314 \\
\hline Preeclampsia & $3(4.28)$ & $4(1.9)$ & 0.507 \\
\hline Eclampsia & $1(1.42)$ & 0 & 0.563 \\
\hline Oligohydramnios & $10(14.28)$ & $6(2.85)$ & 0.0004 \\
\hline Fetal growth restriction & $14(20)$ & $15(7.14)$ & 0.0022 \\
\hline Placental abruption & 0 & $3(1.42)$ & 0.7379 \\
\hline Stillbirth & $1(1.42)$ & $3(1.42)$ & 0.5609 \\
\hline
\end{tabular}

Table 3: Association of first trimester uterine artery pulsatility index with fetal birth weight.

\begin{tabular}{|lll|}
\hline $\begin{array}{l}\text { Birth } \\
\text { weight } \\
\text { (grams) }\end{array}$ & $\begin{array}{l}\text { PI } \geq 1.5(\mathrm{~N}=70) \\
\text { Frequency }(\%)\end{array}$ & $\begin{array}{l}\text { PI }<1.5(\mathrm{~N}=210) \\
\text { Frequency }(\%)\end{array}$ \\
\hline $\mathbf{1 0 0 0}$ & $1(1.4)$ & 0 \\
\hline $\mathbf{1 0 0 0 - 1 4 9 9}$ & 0 & $1(0.4)$ \\
\hline $\mathbf{1 5 0 0 - 1 9 9 9}$ & $1(1.4)$ & $8(3.8)$ \\
\hline $\mathbf{2 0 0 0 - 2 4 9 9}$ & $17(24.28)$ & $26(12.38)$ \\
\hline $\mathbf{2 5 0 0 - 2 9 9 9}$ & $19(27.14)$ & $90(42.8)$ \\
\hline $\mathbf{3 0 0 0 - 3 4 9 9}$ & $25(35.7)$ & $63(30)$ \\
\hline $\mathbf{3 5 0 0 - 3 9 9 9}$ & $5(7.14)$ & $21(10)$ \\
\hline $\mathbf{> 4 0 0 0}$ & $2(2.8)$ & $1(0.4)$ \\
\hline P value $=\mathbf{0 . 0 2 3}$ & \\
\hline
\end{tabular}

A study done by Ratiu et al which analysed uterine artery Doppler between 19 to 22 weeks of gestation reported 26 cases with oligohydramnios among 1472 women studied. The prevalence of oligohydramnios in their study was $1.8 \% .{ }^{17}$ The number of patients with oligohydramnios in our study was high as it was seen to develop along with other complications such as gestational hypertension or preeclampsia and in few cases along with FGR.

Table 4: Area under curve test result variable(s): PI value.

\begin{tabular}{|lll|}
\hline Area & Standard error & Asymptotic significance \\
\hline $\mathbf{0 . 6 5 9}$ & 0.039 & 0.000 \\
\hline
\end{tabular}

Table 5: Asymptotic 95\% confidence interval.

\begin{tabular}{|ll|}
\hline Parameters & \\
\hline Lower bound & Upper bound \\
\hline 0.582 & 0.736 \\
\hline
\end{tabular}

\section{Gestational hypertension}

In the present study, $13.2 \%$ of antenatal women developed gestational hypertension. Most of them (7.3\%) developed gestational hypertension in the third trimester of pregnancy. It has been noticed that $7.14 \%$ of antenatal women with abnormal first trimester uterine artery 
pulsatility index developed gestational hypertension when compared to $1.9 \%$ women with normal Doppler. Therefore, $\mathrm{p}$ value was insignificant in this case, which was 0.0314 . This finding is consistent with study done by Plasencia et al which showed that GHTN developed only in $1.8 \%$ of cases among 6015 study participants. ${ }^{16}$

\section{Preeclampsia}

Preeclampsia developed in $10.29 \%$ of the total study population. It developed more commonly in the third trimester $(7.3 \%)$ of pregnancy, and it was also seen in $4.28 \%$ of antenatal women who had abnormal first trimester uterine artery pulsatility index, when compared to $1.9 \%$ of women who had normal uterine artery Doppler. Therefore, $\mathrm{p}$ value was insignificant, which was 0.507 . A meta-analysis done by Velathur et al reported $26.4 \%$ and $47.8 \%$ sensitivities of preeclampsia and early onset preeclampsia respectively. ${ }^{15}$ Study done by Plasencia et al. showed that PE developed only in $1.8 \%$ of cases among 6015 study participants and more women (12.6\%) developing FGR without any GTN or PE. ${ }^{16}$ A study done by Mojgan et al where uterine artery Doppler was studied between 16-22 weeks for the development of adverse pregnancy outcomes, preeclampsia was found to have a significant $\mathrm{p}$ value $(0.001) .{ }^{18} \mathrm{~A}$ study done by Ratiu et al which analysed uterine artery Doppler between 19 to 22 weeks of gestation reported 16 cases of PE among 1472 women studied. The prevalence of PE in their study was $1.1 \% .{ }^{17}$

\section{Eclampsia}

In the present study, only 1 woman developed eclampsia $(1.47 \%)$ among the total study population. In the second trimester of pregnancy, she was noted to have abnormal first trimester uterine artery pulsatility index. Therefore, $P$ value was insignificant in this case, which was 0.563 .

\section{Placental abruption}

In the present study placental abruption developed in $4.41 \%$ of antenatal women. About $2.94 \%$ developed it in the third trimester of pregnancy and it was observed that antenatal women with normal uterine artery doppler had developed abruption. Therefore, $\mathrm{p}$ value was insignificant being 0.7379 . A meta-analysis done by Velathur et al reported sensitivity of $44.4 \%$ for placental abruption. ${ }^{15}$

\section{Stillbirth}

About $5.88 \%$ of antenatal women delivered stillborn babies in the third trimester of pregnancy. It was observed that $1.42 \%$ of women with both normal and abnormal Doppler's delivered stillborn babies. Therefore, making the $\mathrm{p}$ value insignificant which was 0.5609. A meta-analysis done by Velathur et al reported low predictive accuracy for stillbirth, with a sensitivity of $14.5 \% .^{15}$

\section{Period of gestation at delivery}

In this study, it was found that the maximum number $(50.3 \%)$ of antenatal women delivered at early term (between 37 to $38+6$ weeks) of gestation. This was followed by $34.2 \%$ who delivered at full term (39 to $40+6$ weeks). There were about $0.35 \%$ of antenatal women who delivered at very preterm (28 to $31+6$ weeks) and also during the late term period ( $>41$ weeks). In our study, it was observed that about $48 \%$ of women with normal first trimester pulsatility index delivered during early term. The maximum number of women with abnormal Doppler also delivered during this period constituting about $57.1 \%$. No women in our study were seen to deliver at the very preterm period (28 to $31+6$ weeks) among the women who had normal Doppler's. And about $1.42 \%$ of women having abnormal pulsatility index were seen to deliver during this period of gestation. As per data from the study done by Costa et al the mean gestational age of delivery of their cases was $38.4 \pm 1.3 .^{19}$ According to a study done by Mojgan et al it has been reported that 9 women $(47 \%)$ with preeclampsia had preterm delivery ( 7 delivered between 32 to 37 weeks and 2 delivered before 32 weeks) and 8 women ( $88 \%$ ) among them had abnormal dopplers. ${ }^{18}$ Napolitano et al. have found significant $\mathrm{p}$ value $(<0.0001)$ when development of PE was corelated with gestational age at birth. $^{20}$

\section{Sensitivity, specificity, positive and negative predictive value}

In our study, it was found that the sensitivity of first trimester uterine artery pulsatility index was $42.03 \%$ and specificity was $80.57 \%$. The positive predictive value was $41.43 \%$ and negative predictive value was $80.95 \%$. Therefore, the ROC curve in this study was significant for first trimester uterine artery pulsatility index in the prediction of pregnancy complications like gestational hypertension, preeclampsia, eclampsia, placental abruption and adverse outcomes such as stillbirth and low birth weight neonates. According to Barati when first trimester uterine artery pulsatility index was taken to be less than 90th percentile, the sensitivity was found to be $48 \%$ with a false positive rate of $8 \%$ in predicting early onset preeclampsia and $26 \%$ with a false positive rate of $7 \%$ for late onset preeclampsia. According to study by Khong et al an abnormal uterine artery pulsatility index in the first trimester was predictive of preeclampsia and early- onset preeclampsia with sensitivities of $26.4 \%$ and $47.8 \%$, respectively. ${ }^{21}$ Fetal growth restriction was predicted at $15.4 \%$, whereas early-onset FGR was associated with a higher sensitivity of $39.2 \%$. The sensitivity achieved for placental abruption was $44.4 \%$. First-trimester Doppler indices showed a low predictive accuracy for stillbirth, with a sensitivity of $14.5 \%$. First trimester uterine artery pulsatility index has a significant value in the diagnosis of pregnancy complications and adverse outcomes. Identification of abnormal pulsatility index was higher in nulliparous women and women with 
higher age groups. Uterine artery pulsatility index done in the first trimester of pregnancy showed significant correlation to pregnancy complications like gestational hypertension, oligohydramnios and fetal growth restriction. Uterine artery pulsatility index screening at 11 to 14 weeks scan showed early detection of hypertensive disorders in pregnancy but had no correlation to the mode of delivery. The ROC curve to determine the sensitivity and specificity of first trimester uterine artery pulsatility index for the prediction of pregnancy complications and adverse outcomes showed fair accuracy. An abnormal Doppler finding in the first trimester helps in initiation of recommended aspirin therapy during pregnancy to prevent adverse outcomes.

\section{CONCLUSION}

As hypertensive disorders of pregnancy pose a great risk of maternal and fetal morbidity and mortality, an evolution of Doppler studies have proven to be beneficial. Doppler ultrasound was found to be a valuable modality in the evaluation of fetal and placental circulation as well as in the prediction of pregnancy outcomes. According to the receiver operating characteristic curve obtained in our study, sensitivity and specificity of first trimester uterine artery pulsatility index was predictive for pregnancy complications and adverse outcomes.

\section{ACKNOWLEDGEMENTS}

Authors would like to thank the patients who consented to participate in the study.

\section{Funding: No funding sources}

Conflict of interest: None declared

Ethical approval: The study was approved by the Institutional Ethics Committee

\section{REFERENCES}

1. Benigni A, Gregorini G, Frusca T. Effect of low-dose aspirin on fetal and maternal generation of thromboxane by platelets in women at risk for pregnancy-induced hypertension. $\mathrm{N}$ Engl $\mathrm{J}$ Med. 1989;321(6):357-62.

2. Chien P, Arnott N, Gordon A, et al. How useful is uterine artery Doppler flow velocimetry in the prediction of pre-eclampsia, intrauterine growth retardation and perinatal death? An overview. Br J Obstet Gynaecol. 2000;107(2):196-208.

3. Albaiges G, Missfelder-Lobos H, Lees C. One- stage screening for pregnancy complications by color Doppler assessment of the uterine arteries at 23 weeks' gestation. Obstet Gynecol. 2000;96(4):559-64.

4. Bujold E, Roberge S, Lacasse Y. Prevention of preeclampsia and intrauterine growth restriction with aspirin started in early pregnancy: a meta-analysis. Obstet Gynecol 2010;116(2):402-14.
5. Roberge S, Villa P, Nicolaides K. Early administration of low-dose aspirin for the prevention of preterm and term preeclampsia: a systematic review and meta-analysis. Fetal Diagn Ther. 2012; 31(3):141-6.

6. Koopmans C, Bijlenga D, Groen H, et al. Induction of labour versus expectant monitoring for gestational hypertension or mild pre-eclampsia after 36 weeks' gestation (HYPITAT): a multicentre, open-label randomized controlled trial. Lancet. 2009;374(9694): 979-88.

7. James P, Nelson-Piercy C. Management of hypertension before, during and after pregnancy. Heart. 2004;90(12):1499-504.

8. Hutcheon J, Lisonkova S, Joseph K. Epidemiology of pre-eclampsia and the other hypertensive disorders of pregnancy. Best Pract Res Clin Obstet Gynaecol. 2011;25(4):391-403.

9. Khan KS, Wojdyla D, Say L. WHO analysis of causes of maternal death: a systematic review. Lancet 2006;367(9516):1066-74.

10. Milne F, Redman C, Walker J. The preeclampsia community guideline (PRECOG): How to screen for and detect onset of preeclampsia in the community. BMJ. 2005;330(7491):576-80.

11. Steegers E, Von Daldelszen P, Duvekott J, et al. Preeclampsia. Lancet. 2010;376(9741):631-44.

12. Kane SC, da Silva CF, Brennecke S. First trimester biomarkers in the prediction of later pregnancy complications. Biomed Res Int. 2014;2014:807196.

13. Everett T, Lees C. Beyond the placental bed: placental and systemic determinants of the uterine artery Doppler waveform. Placenta. 2012;33(11):893901.

14. Askie L, Duley L, Henderson-Smart D. Antiplatelet agents for prevention of pre-eclampsia: a metaanalysis of individual patient data. Lancet. 2007; 369(9575):1791-8.

15. Velauthar L, Plana M, Kalidindi M. First-trimester uterine artery Doppler and adverse pregnancy outcome: a meta-analysis involving 55,974 women. Ultrasound Obstet Gynecol 2014;43(5):500-7.

16. Plasencia W, Maiz N, Poon L, et al. Uterine artery Doppler at $11+0$ to $13+6$ weeks and $21+0$ to $24+$ 6 weeks in the prediction of pre-eclampsia. Ultrasound Obstet Gynecol. 2008;32(2):138-46.

17. Ratiu D, Hide-Moser K, Morgenstern B, et al. Doppler indices and notching assessment of uterine artery between the 19th and 22nd week of pregnancy in the prediction of pregnancy outcome. Lancet. 2019;33(6):2199-204.

18. Barati M, Shahbazian N, Ahmadi L. Diagnostic evaluation of uterine artery Doppler sonography for the prediction of adverse pregnancy outcomes. J Res Med Sci. 2014;19(6):515-9.

19. Gadelha-Costa A, Spara P, Costa T. Uterine arteries resistance and pulsatility indices at the first and second trimesters of normal pregnancies. Radiol Bras. 2010;43(3):161-5. 
20. Napolitano R, Melchiorre K, Arcangeli T. Screening for pre-eclampsia by using changes in uterine artery Doppler indices with advancing gestation. Prenat Diagn. 2012;32(2):180-4.

21. Khong SL, Kane SC, Brennecke SP. First-trimester uterine artery Doppler analysis in the prediction of later pregnancy complications. Dis Markers. 2015; 2015:679730.

22. Kennedy AM, Woodward PJ. A Radiologist's Guide to the Performance and Interpretation of Obstetric Doppler US. Radio graphics. 2019;39(3):893-910.
23. Poon LC, Shennan A, Hyett JA, Kapur A, Hadar E, Divakar $\mathrm{H}$, et al. The international federation of gynaecology and obstetrics (FIGO) initiative on preeclampsia: A pragmatic guide for first trimester screening and prevention. Int J Gynaecology Obstet. 2019;145(1):1-3.

Cite this article as: Jayson JA, Mandrelle K, Dhar T, Singla S. First trimester uterine artery Doppler screening in the prediction of adverse pregnancy outcomes. Int J Reprod Contracept Obstet Gynecol 2021;10:3933-41. 